\title{
VIOLENCIA DE GÉNERO Y MASCULINIDAD EN CHILE: UNA REVISIÓN DE LAS POLÍTICAS PÚBLICAS EN DEMOCRACIA (1990-2014)
}

\author{
Javier Maravall Yáguez \\ javamaravall@hotmail.com \\ Universidad de Santiago de Chile - Chile
}

Recibido: 27-02-2016

Aceptado: 25-04-2016

\section{Resumen}

El artículo analiza la evolución de las políticas públicas implementadas en democracia (19902014) en materia de violencia machista e intervención con población masculina. Por una parte, interpreta desde la perspectiva de género, los mensajes y acciones a la hora de incluir a los hombres como parte de la solución del problema y de qué manera éstos reforzaron o no modelos masculinos sexistas y desigualitarios. Por otra, identifica y describe cómo la principal institución encargada de garantizar la protección de los derechos fundamentales de las mujeres (Servicio Nacional de la Mujer, SERNAM) abordó la problemática, a través del análisis de sus propuestas y orden de prioridades, así como las dificultades que se fueron presentando.

Palabras Clave: Masculinidad, violencia de género, políticas públicas, Servicio Nacional de la Mujer, Chile.

\begin{abstract}
The article analyses the development of the public policies implemented in Chilean democracy (1990-2014) on the subject of gender violence and intervention on male population. On the one hand, it interprets, from the perspective of gender, messages and actions when including men as part of the solution of the problem and how they reinforced (or not) unequal and sexist male role models. On the other hand, it identifies and describes how the main institution entrusted to guarantee the protection of the fundamental rights of women (National Women's Service SERNAM) addressed the questions, through the analysis of their proposals and priorities as well as difficulties found.
\end{abstract}

Keywords: Ma Masculinity, gender violence, public policies, National Women's Service, Chile. 


\section{Introducción}

En la actualidad, distintas cifras sobre violencia de género se han ido instalando como prueba material de las complejas relaciones que estructuran la sociedad en Chile, muestra de ello son las cuarenta y cinco mujeres que perdieron la vida a manos de sus parejas durante el año 2015 (-diciembre ${ }^{1}$-), datos que se estiman superiores si tenemos en cuenta los casos de muertes por violencia no resueltos. Este hecho nos obliga a repensar la manera en que se ha abordado el problema en los últimos veinticinco años y en qué medida las acciones hasta el momento, han tenido un verdadero efecto sobre un problema que, lejos de resolverse, parece incrementarse, especialmente entre la población adolescente ${ }^{2}$. Pero también es imprescindible analizar de qué manera se ha legitimado o reproducido lo masculino en la sociedad chilena y si ello ha contribuido a incrementar o paliar comportamientos de maltrato o estereotipos que conducen a relaciones de poder y subordinación.

En Chile, la percepción social del origen de la conducta de los maltratadores se ha explicado a través de tres circunstancias: 1. La baja autoestima del sujeto, junto con la necesidad de superponerse a la pareja como reafirmación de su seguridad. 2. Como una conducta alterada por el consumo de drogas y alcohol. 3. Como la consecuencia de algún tipo de trastorno de orden psicopático y emocional (esquizofrénicos y maniacodepresivos) que inhabilitaría al hombre de por sí a la hora de controlar sus impulsos e instintos primarios: "la real toma de conciencia pasa por no ver a los maltratadores como individuos extraterrestres, enfermos o locos, sino como varones normales que tienen privilegios y habilidades aprendidas" (Maravall, Covas y Bonino, 2009: 52). En esta línea, aparecerían dos supuestos que convendrían destacar por separado: Uno, referido al ámbito socio-sanitario: el control de impulsos para no agredir exige autoestima alta, herramientas de autocontrol y conocimiento psíquico pero también, una situación social digna: "El debilitamiento de la condición masculina -relacionado con la precarización de las condiciones laborales, y sus efectos económicos-, es compensado por la fuerza física" (Burin, Jiménez y Meler, 2007: 34).

En segundo lugar, el que tiene que ver con los comportamientos y actitudes derivados del sistema de creencias culturales, éticas, religiosas, o sociales que estarían interiorizadas tanto en hombres como en mujeres y operarían bajo un automatismo que podría impulsar o desencadenar conductas maltratadoras y/o discriminatorias. Es precisamente en este punto, donde entraría en juego la influencia y el impacto de los mensajes públicos en la sociedad chilena, en cuanto al significado de la violencia de género, las causas por las que se produce y el

\footnotetext{
${ }^{1}$ www.sernam.cl/feminicidios2015 [30/12/2015].

${ }^{2}$ En noviembre de 2012, el Ministerio de Salud publicó una hoja de ruta de lo que debían ser las políticas públicas de atención a la salud en el período 2011-2020. Entre los objetivos prioritarios se encontraba el de disminuir el alarmante aumento de violencia entre la población joven y adolescente: "Contribuir a disminuir un $33 \%$ la tasa trienal de feminicidios en mayores de 15 años (de 1,8 a 1,2 por 100 mil)" (SERNAM, 2012: 6).
} 
perfil de hombre que la ejerce. El rol del Estado, en cuanto a institución política y referente ciudadano, resulta fundamental en la legitimación de las conductas sociales y, en este caso, en la interpretación y la manera de entender la convivencia entre hombres y mujeres (espacios existenciales) y muy especialmente, el que se refiere al hogar, frecuentemente representado como lugar idílico y exclusivamente privado. Precisamente si es en este ámbito donde, por lógica, reside el núcleo de la desigualdad y los conflictos interpersonales, las instituciones de alguna manera tendrán que llegar a este espacio, como garantía del pleno ejercicio de los derechos fundamentales y de la convivencia ciudadana. Pero también el Estado, ha de configurarse como un catalizador de las demandas emanadas de la sociedad, garantizando instancias que permitan un diálogo permanente y a su vez, otorgando una dimensión política a la violencia machista. Al igual que sucede con los fenómenos de alta complejidad históricosocial en donde intervienen diversos factores, se nos plantean diferentes interrogantes a resolver: ¿De qué manera las instituciones públicas en democracia han incluido a los hombres en sus políticas contra la violencia de género? ¿Cuáles fueron las prioridades de acción y las dificultades en este tránsito? ¿Qué mensajes se utilizaron en las campañas publicitarias institucionales sobre el significado de la violencia machista? ¿los antecedentes ocurridos durante la dictadura militar en relación a la violencia ejercida contra las mujeres, influyeron de alguna manera en este proceso?

\section{Aspectos metodológicos}

Para la realización de esta investigación, se han consultado tres tipos de fuentes. 1. Documentación original del Servicio Nacional de la Mujer (SERNAM) relativa a las acciones y propuestas implementadas en materia de violencia de género e intervención con hombres (19912014): programas de igualdad, declaraciones y memorias oficiales, informes y resultados, programaciones de intervención, cifras y diagnósticos oficiales. 2. Archivos y documentos publicados por redes y organizaciones sociales representativas de hombres y mujeres durante el período de estudio seleccionado (Red de Estudios de Masculinidad ${ }^{3}$ e Instituto de la Mujer ${ }^{4}$ ) así

\footnotetext{
${ }^{3}$ La Red de Estudios de Masculinidad (1998) tiene su sede en la Facultad Latinoamericana de Ciencias Sociales (FLACSO) y está compuesta por académicos y especialistas centrados en los estudios sobre Masculinidad e intervención con hombres: Humberto Abarca (Universidad de Chile), Marcos Fernández (Universidad Católica), Gabriel Guajardo (Universidad de Chile), José Olavarría (FLACSO-Chile), Carla Donoso (Universidad de Chile), Rodrigo Parrini (Universidad de Chile) y Teresa Valdés (FLACSOCHILE) entre otros. Esta propuesta nació con el ánimo de impulsar espacios de reflexión y producción de conocimiento en lo relativo a "las problemáticas de la masculinidad y los hombres, así como favorecer el intercambio entre investigadores de las identidades masculinas y profesionales involucrados en programas de acción con hombres". Ver www.eurosur.org/FLACSO/masculinidad.htm.

${ }^{4}$ El Instituto de la Mujer (1987), destacó por su trabajo en el campo legal de los derechos de las mujeres (Violencia, Derechos Reproductivos y Salud), en la creación de espacios de trabajo y producción literaria,
} 
como bibliografía especializada (Olavarría 2001, Aguayo 2011, Bonino 2009, Connell 1995, Bourdieu, 2000, Kaufam, 2001). 3. Campañas informativas y publicitarias realizadas por el SERNAM durante el período 2005-2014. La combinación de las tres fuentes responde al objetivo de indagar de qué manera, las políticas públicas han asumido el problema en base a las demandas emanadas los agentes sociales implicados en el tema y, cómo ello quedó reflejado, especialmente, en los contenidos de las campañas de difusión informativa.

Por otra parte, la interpretación de la información se ha sustentado en la Teoría Feminista contemporánea (Maquieira, 2004, Durán, 2012, Duby y Perrot, 2000) que propone la inclusión de la perspectiva de género y el principio de Transversalidad (Mainstreaming ${ }^{5}$, Comisión Europea, 1996), como enfoque metodológico para comprender la evolución de una determinada sociedad. Ello supone la aceptación de dos premisas: las comunidades humanas se han configurado desde sus orígenes en dos espacios dicotómicos diferenciados (público-hombre, privado-mujer), y cuyas relaciones de poder entre sí, operarían bajo una estructura de dominio vs subordinación en favor de los hombres (Patriarcado); dos, la asignación/imposición de constructos identitarios que dicho sistema habría otorgado a cada sexo (lo masculino y lo femenino) para legitimarse y mantenerse.

Asimismo, se han utilizado conceptos y categorías ya definidas como:

- Masculinidad hegemónica (Bonino, 2009): entendido como la manera predominante de percibir lo masculino representado en los discursos y acciones de quienes sustentan en el poder: en la "masculinidad dominante, los hombres se caracterizan por ser personas importantes, activas, autónomas, fuertes, potentes, racionales, emocionalmente controladas, proveedores en la familia y su ámbito de acción está en la calle" (Olavarría; Parrini, 2000: 11);

- Violencia doméstica y/o Intrafamiliar: definida como "todos los actos de violencia física, sexual, psicológica o económica que se producen en la familia, en el hogar o entre cónyuges" (Council of Europe Treatry Series, 2011: 5);

- Violencia contra la Mujer: como cualquier acto violento basado en "la pertenencia al sexo femenino que tenga como resultado un daño físico, sexual o psicológico para la mujer"6.

y en el asesoramiento a los responsables políticos para "el diseño e implementación de políticas públicas contra la violencia intrafamiliar" (Instituto de la Mujer,1993).

${ }^{5}$ La Comisión Europea definió el Mainstreaming como un enfoque integrado aplicable tanto a la investigación como la implementación de políticas públicas y, cuyo propósito es el de garantizar la plena igualdad de oportunidades entre hombres y mujeres mediante la comprobación de tres aspectos: Si se han aplicado cambios formales en la Ley para reparar las desigualdades de género pre-existentes; Si se han implementado medidas paralelas con la ciudadanía para facilitar la adaptación entre la realidad legislativa y social. Si se han diseñado estrategias específicas para transformar los elementos (culturales, políticos y económicos) que hayan originado o favorecido las desigualdades de género. Ver Comisión Europea (2008: 10-11).

${ }^{6}$ Ver Resolución 48/104 del 20 de diciembre de 1993, Asamblea General de Naciones Unidas (ONU). Ver www.un.org. 
- Violencia de Género y/o Violencia Machista: como aquellos actos que atentan contra los derechos humanos de las mujeres por su condición de género, siguiendo los lineamientos establecidos en las conferencias de Belem do Pará (1994) y Beijing (1995), ambas ratificadas por Chile en 1996 y la definición del Alto Comisionado de las Naciones Unidas para los Refugiados (UNFPA $\left.{ }^{7}, 2000\right)$.

- Finalmente, el término Igualdad, referido no solo a la igualdad de derechos y oportunidades, sino también a la equivalencia existencial que permita que hombres y mujeres vivan y convivan en una misma escala jerárquica en cuanto a ciudadanos. Respetando las diferencias de sexo, se trata de analizar las desigualdades que basándose en estas diferencias, han atribuido a los hombres un lugar predominante en las relaciones de poder.

\section{Debates teóricos: Masculinidad, Violencia y Políticas Públicas}

Los primeros debates en torno a la Masculinidad y la necesidad de incluir a los hombres en las políticas de igualdad y prevención de violencia, surgieron en Chile a finales de los noventa, por iniciativa de un grupo de académicos y profesionales de las áreas sociales ligados a la Facultad Latinoamericana de Ciencias Sociales (FLACSO), la Universidad de Chile y la Universidad Católica. Entre ellos, se encontraban el sociólogo José Olavarría, el antropólogo Gabriel Guarjardo Soto, el psicólogo Víctor Valenzuela y el historiador Marcos Fernando Labbé En 1998, junto con el apoyo de otras profesionales especializadas en género como Teresa Valdés (subdirectora académica de FLACSO-Chile), formaron la primera Red de Estudios de Masculinidad, un punto de encuentro, debate y producción académica desde donde partirían las primeras propuestas para incluir a los hombres en las políticas públicas.

Por una parte, los debates se centraron, en reflexionar sobre los avances de las mujeres durante la década de los noventa en contraposición con la actitud estática de los hombres en el proceso -"históricamente, las políticas públicas han sido hombre-céntricas para proteger privilegios de los hombres"- (Aguayo; Sadler, 2011: 25), pero también sobre el efecto que ello estaba teniendo en la disminución o incremento de las tasas de violencia contra las mujeres en el país. Efectivamente, la ausencia de políticas públicas para movilizar a los hombres por la igualdad y la no violencia, fue una de las conclusiones de los primeros encuentros realizados por la Red en 2000 y 2001, pese a que Chile se suscribiera a los acuerdos internacionales que ya recomendaban acciones en este sentido (Beijing, 1995). Por tanto, el razonamiento se sustentaba en que si en el colectivo masculino no se había producido un cambio de dirección, fomentada desde las instancias públicas, difícilmente se lograrían resultados favorables a fortalecer la plena igualdad, sino más bien todo lo contrario: resistencias masculinas: "Todos

\footnotetext{
${ }^{7}$ En el año 2000, el UNFPA definió la Violencia de Género como "violación de los derechos humanos de las mujeres". Ver www.ohchr.org
} 
los hombres, tanto en lo más alto como en lo más bajo de la escala social, encuentran que los cambios en la condición femenina amenazan su virilidad y las relaciones de poder" (Burin: 34 ).

Por otra parte, se planteó la necesidad de que los varones en su conjunto, fueran objeto de estudio, y no solo en lo relativo a la violencia sino en todas las áreas posibles, como la Sexualidad, Salud o la Paternidad co-responsable. En otras palabras, la idea de que las instituciones debían impulsar políticas de intervención integral con la población masculina empezó a tomar fuerza y ello, quedó reflejado en las diferentes recomendaciones que la Red realizó al SERNAM a través de sus estudios y publicaciones, por ejemplo, mediante la educación en modelos masculinos igualitarios desde la más temprana infancia (corresponsabilidad en los cuidados, trabajo doméstico, resolución pacífica de conflictos, etc.). Estas propuestas estuvieron acordes con los debates que se produjeron en otros contextos internacionales, como Gran Bretaña o España.

Un ejemplo lo encontramos en las aportaciones de los sociólogos británicos Harry Christian (“The Making of Anti-sexist Men”, London, 1994) y Rewan Connell (“Masculinities”, Cambridge, 1995). Sus planteamientos proponían interrogar desde la pausa psicoanalítica, lo que subyace a las distintas formas de violencia ejercidas por los hombres, especialmente cuando éstos conviven en pareja. En este sentido, se destacaba una relación estrecha entre los constructos educativos aprendidos y la socialización afectivo-sexual en la primera infancia (0-6 años), con las estructuras de comportamiento y percepción en la fase adulta. Bajo esta hipótesis, si un niño naturaliza espacios de privilegio desde la escuela primaria (por ejemplo, al disponer de más espacio y protagonismo en la cancha de fútbol), en el futuro, con mayor probabilidad tendrá dificultades de relacionarse equitativamente con las mujeres de su entorno. También Michael Kaufam ("Effective Education With Boys and Young Men to Help End Violence", Canadá, 2001), en sus sucesivos estudios sobre violencia y masculinidad, realiza una serie de planteamientos que resultan reveladores. Coincidiendo con las hipótesis del psiquiatra y especialista en masculinidades, Luis Bonino ${ }^{8}$, existiría una potencialidad entre los hombres que ocupan espacios de privilegio, de generar mecanismos de violencia y/o maltrato -conscientes o subconscientes- contra aquellas personas (las mujeres) que los cuestionasen.

Se podría pensar entonces que dicha reacción tendría que ver con una respuesta mecánica de la psique para no perder calidad de vida (comodidades y gracias domésticas), tal y como ocurriría en buena parte de las especies animales que tratan de defender su territorio o sustento. Por esta regla, se presupone que la mayoría de los hombres, socializados en idearios de género patriarcales, estarían por inercia dirigidos a ocupar espacios de protagonismo y tratar de ejercer un "poder de facto tanto en el espacio público como privado" (Bourdieu, 2000: 58); por ende, dicha circunstancia en sí misma, entrañaría un riesgo potencial de la mayoría de los hombres de ejercer algún tipo de violencia a lo largo de su historia de vida, especialmente en aquellos momentos en donde su posición ventajosa fuera cuestionada. A ello se suma el hecho de que,

\footnotetext{
${ }^{8}$ Luis Bonino es responsable del Centro de Estudios de la Condición Masculina (CECOMAS, Madrid) y especialista en Violencia de Género y Masculinidad en la sociedad actual. Ver www.cecomas.com
} 
históricamente, se ha dado por sentado una contraposición de género en donde hombres y mujeres, por lógica natural, estarían "condenados" a ser diferentes y no terminar de entenderse nunca, una justificación frecuentemente utilizada como origen y/o desencadenante de la violencia machista.

\section{Antecedentes históricos: masculinidad y violencia de género durante la dictadura militar (1973-1990)}

La dictadura del general Augusto Pinochet Ugarte y sus diecisiete años de existencia (1973-1990), bien podrían representar la máxima expresión del hombre patriarcal y de la violencia machista, si analizamos la "manera en la que se reprimió a las mujeres política y socialmente" (Bunster, 1983: 20; Rojas, 1989: 23-73) y los arquetipos masculinos y femeninos que se legitimaron en el proceso de institucionalización de la Junta Militar. En efecto, las declaraciones y discursos oficiales apuntaban a la recuperación del modelo católico de familia y los viejos paradigmas masculinos y femeninos patriarcales:

-Como hombre, como soldado y como gobernante, no creo poder rendirles mayor homenaje que el de recordar la responsabilidad que significa para los hombres de armas la fe que ellas depositaron públicamente en nosotros... (la mujer) debe desarrollar su auténtica personalidad y proyectar sobre la sociedad el caudal de intuición y riqueza afectiva que le es propio. Consideramos por eso que una auténtica participación de la mujer en la vida nacional deber ser ejercida con respeto a sus características ${ }^{9}$.

En este contexto, los agentes represores $\left(\mathrm{DINA}^{10} \mathrm{y} \mathrm{CNI}^{11}\right.$ ) utilizaron "dicha fuente de legitimación" para justificar todo tipo de actos violentos contra aquellas mujeres que de alguna forma cuestionasen o trasgrediesen "su espacio natural", por ejemplo, si militaban social o políticamente contra la dictadura. Ello quedó materializado en toda una amalgama de violencias diseñadas específicamente para amedrentarlas y que quedarían reflejadas y categorizadas como "Violencia Sexual contra las Mujeres", cuando en 2004 se publicó el Informe Valech". Este

\footnotetext{
${ }^{9}$ El fragmento pertenece al discurso pronunciado por el Comandante en Jefe de las Fuerzas Armadas y Presidente de la Junta de Gobierno, Augusto Pinochet, el día 24 de Abril de 1974, en un acto realizado en Santiago. Ver Valdés (1987: 25).

${ }^{10}$ La Dirección de Inteligencia Nacional (DINA) se creó el 14 de junio de 1974 por el decreto ley № 521 y funcionó hasta finales de 1977. Su dirección estaba a cargo del coronel Manuel Contreras Sepúlveda y su principal objetivo fue reprimir extraoficialmente los focos de disidencia que pudieran producirse dentro y fuera de Chile. Ver Ministerio del Interior, Gobierno de Chile (1991).

${ }^{11}$ La Central Nacional de Informaciones se creó en agosto de 1977 mediante el decreto ley № 1878 , y funcionó hasta febrero de 1990. Aunque en su estructura y composición la DINA y la CNI fueron la misma organización, en términos represivos tuvo un carácter más selectivo debido a dos factores: la presión internacional y la disminución de la actividad opositora (Ibíd.: 627).

${ }^{12}$ El Informe de la Comisión Nacional sobre Prisión Política y Tortura (ICNPT) fue publicado en 2004 bajo el mandado de Ricardo Lagos Escobar y actualizado en 2011 (Etapa de Reconsideración).
} 
trabajo recogía un total de 5.121 experiencias que fueron relatadas y denunciadas por las propias víctimas, pero también por las diferentes organizaciones sociales a las que pertenecieron. En otras palabras, la necesidad de nombrar y denunciar lo que les sucedió en dictadura, partió del deseo de dignidad, justicia y reparación que las mismas afectadas reclamaron para sí y sus familiares, lo que generó un movimiento social espontáneo que permitiría la aparición de nuevos lugares de encuentro desde donde además, se reflexionaría sobre los roles de género y su relación con la violencia y discriminación machista. Pero las organizaciones sociales de mujeres en este período, aunque también refirieron al problema de la violencia ocurrida en el ámbito del hogar (en sus documentos se utiliza el término violencia doméstica) centraron sus esfuerzos sobre todo en la denuncia de la represión militar y el trabajo con mujeres para facilitar su independencia y bienestar, más allá de establecer un debate sobre la figura del hombre maltratador (o torturador) y los elementos que podían desencadenar los distintos tipos de violencia ejercida contra las mujeres.

Por un lado, florecerían las organizaciones de Derechos Humanos (Agrupación de Familiares de Detenidos-desaparecidos -1974-, Agrupación de Familiares de Ejecutados Políticos -1974-, Agrupación de familiares de Presos Políticos -1975-, Mujeres Por la Vida -1978-, Comité de Defensa de los Derechos del Pueblo -1984-, etc.) como respuesta a la represión pinochetista y cuyo liderazgo femenino fue indiscutible en la medida que fueron los hombres mayormente perseguidos, detenidos y ejecutados. Madres, esposas, hermanas e hijas "asumieron la labor de denuncia y búsqueda de sus seres queridos" (Palestro, S., Gaviola E., Largo E., 1994: 43), agrupándose en diversas iniciativas desde donde también se abrirían espacios para abordar la condición de la mujer en todas las esferas de su desarrollo desde la formación y la toma de conciencia de sus derechos fundamentales: "talleres de derechos sexuales y reproductivos, apoyo psicoterapéutico a víctimas de la violencia sexual, asesoramiento legal para denunciar casos tortura y desaparición forzada..."(Aharonian, 2003: 20).

Por otro, las organizaciones feministas que plantearon un análisis más profundo en lo relativo a la condición de la mujer y que serían un referente posterior en el diseño de políticas públicas finalizada la dictadura. Un ejemplo lo encontramos en la aparición del Movimiento Pro-emancipación de la Mujer (Mench, 1983). En los lineamientos de su manifiesto fundacional $^{13}$, se incluía el abordaje de la violencia contra las mujeres como una vulneración de los derechos humanos y a la que debía responderse mediante dos tipos de intervención: una, destinada a las víctimas (incluidas las mujeres violentadas por la dictadura) a través de grupos de trabajo centrados en su recuperación psico-social; en segundo lugar, "talleres de formación

Oficialmente se reconocieron 38.254 casos de personas que sufrieron prisión política y tortura. Ver "Informe para la Calificación de Detenidos Desaparecidos, Ejecutados Políticos y Víctimas de Prisión Política y Tortura" (INDL, 2011).

${ }^{13}$ Las fundadoras del Mench fueron Julieta Kirkwood, Margarita Pisano, Eliana Largo, Amparo Claro y Nana Larraín, entre otras. Ver Pisano y Franulic (2009: 52). 
integral"14 (educación sexual, derechos reproductivos, inserción laboral y salud) dirigidos a la población femenina más vulnerable como las pobladoras y trabajadoras del hogar. Los resultados de estas experiencias fueron utilizados para plantear acciones concretas como el Programa de Violencia Doméstica implementado a partir de 1990, que abarcaba desde la atención directa a mujeres maltratadas a través de casas de acogida, a la formación y capacitación de monitores.

Ambas estrategias (infraestructura de atención y prevención mediante la formación) serían utilizados posteriormente por el Servicio Nacional de la Mujer (SERNAM, 1991) en el diseño de sus políticas en democracia. Efectivamente ello fue posible también, tal y como relata una de las fundadoras del Mench, Margarita Pisano, por el "trasvase de feministas de la organización a la institucionalidad" (Pisano, 2009: 165) durante la transición, una circunstancia que generó importantes divisiones entre ellas, pero que significó la recuperación de toda una experiencia social para hacerla pública.

A partir de 1990, la organización entró a formar parte de la Red chilena contra la violencia doméstica y sexual ${ }^{15}$, un punto de encuentro de diversas organizaciones feministas que se mantiene hasta la actualidad, y desde donde se trató de implicar al Estado y a la sociedad civil desde varios frentes (propuestas de "cambios legislativos, demanda de recursos públicos para atender a las víctimas y garantizar sus derechos, difusión de información sobre el significado de la violencia contra las mujeres" ${ }^{\prime 16}$, etc.).

Finalmente, mencionar las aportaciones del Instituto de la Mujer (1987), que destacó por su trabajo en el campo legal de los derechos de las mujeres (Violencia, Derechos Reproductivos y Salud), en la creación de espacios de trabajo y producción literaria, y en el asesoramiento a los responsables políticos para el diseño e implementación de instancias y programas especializados. De hecho, fue la primera organización social que planteó la necesidad de crear

\footnotetext{
${ }^{14}$ Entre 1984 y 1994 la organización implementó los Talleres Integrados Populares de la Mujer (TIP) cuyo objetivo era recoger las experiencias de las mujeres más vulnerables y dar respuesta a sus necesidades más acuciantes. Pero también en este espacio, se proponía la toma de conciencia feminista y del orden patriarcal como generador de violencia contra las mujeres, utilizando como eje vertebrador de la intervención la "interacción entre lo intimo, lo privado y lo público". Ver Abarca (2015: 211-212).

${ }^{15}$ La Red tuvo su aparición en noviembre de 1990, tras el V Encuentro Feminista de Latinoamérica y el Caribe contra la Violencia Doméstica y Sexual celebrado en San Bernardo (Argentina). Estuvo integrada por diversas agrupaciones como La Casa de la Mujer La Morada, La Casa de la Mujer (Valparaíso), Casa Malen y Casa Sofía (Santiago), el Colectivo de monitoras de violencia de género, el Instituto de la Mujer, Agrupación de mujeres de la Florida, ISIS Internacional y la Red de Información sobre los Derechos de la Mujer (RIDEM).

${ }^{16}$ En 1991, la Red respaldó, a través de la organización de una campaña informativa y de apoyo ciudadano, la iniciativa presentada por los diputados Adriana Muñoz y Sergio Aguiló, para la tramitación de una ley específica sobre violencia intrafamiliar. Esta acción tuvo unos resultados fructíferos cuando el gobierno de Patricio Aylwin (1990-1994) invitó a la Red, a formar parte de una comisión de expertos de violencia intra-familiar (creada por decreto presidencial en junio de 1992).
} 
un Protocolo de Atención Directa ${ }^{17}$ (1989) con las mujeres maltratadas, que garantizara la creación de instancias concretas para la atención personalizada. En 1991, y con financiamiento del SERNAM, esta iniciativa se materializó a través de la creación de la Oficina Legal de la Mujer, una instancia que pretendía ofrecer un acompañamiento integral en el proceso de denuncia y tramitación documental en los correspondientes juzgados.

\section{Políticas Públicas Generales en Violencia de Género (1990-2014)}

\subsection{El reforzamiento institucional: la creación del Servicio Nacional de la Mujer}

A partir de 1990, se abrió un nuevo escenario en donde la apertura política y social podía ofrecer mayores posibilidades de abordar la problemática de la desigualdad y la violencia contra las mujeres, aunque con la novedad en este caso, de que sería el Estado el principal promotor y responsable de llevarlo a cabo. Como se ha mencionado anteriormente, a diferencia de lo que ocurrió durante el gobierno militar del General Augusto Pinochet Ugarte (1973-1990), en donde las organizaciones sociales de mujeres ${ }^{18}$ abordaron el problema a espaldas de los gobernantes, a partir de 1990, los sucesivos gobiernos democráticos sí tuvieron presente la necesidad de incorporar el asunto entre las prioridades de la "agenda política" ${ }^{19}$. El efecto más visible lo encontramos en la rápida creación del Servicio Nacional de la Mujer (SERNAM, 3 de enero de 1991) mediante la aprobación de Ley 19.023/91. Este nuevo organismo dependería directamente del Ministerio de Planificación y Cooperación y gozaría de competencias y responsabilidades de nivel similar.

Desde sus inicios, pretendió ser un proyecto pionero en la regulación e implantación de planes y acciones para favorecer la igualdad de oportunidades entre hombres y mujeres. Muestra de ello, fue su aprobación unánime como organismo público en el congreso, una circunstancia que señala al menos, voluntad política del gobierno de Patricio Aylwin (19901994). Sin duda, ello representaba un hito importante en cuanto a que mostraba uno de los

\footnotetext{
${ }^{17}$ El protocolo establece tres pasos a seguir: 1 Tramitación: dejar constancia en la Posta o cuartel de Carabineros de Chile y obtención del parte de lesiones avalada por autoridad sanitaria correspondiente. 2 Tramitación y ratificación de la denuncia: es en este paso en donde las mujeres al no ratificarlas, los casos quedan sobreseídos (lo que avala la necesidad de formar a los funcionarios que se encargan de la atención directa para facilitar que las víctimas, por diferentes motivos, no continúen en el proceso. 3. El juzgado emite una orden para que el Instituto Médico Legal certifique el parte de lesiones. Ver Instituto de la Mujer (1993: 62).

${ }^{18}$ Sobre las aportaciones de las organizaciones de mujeres en relación a la denuncia de la violencia contra las mujeres en dictadura recomendamos el trabajo de Gaviola, Largo y Palestro (1994).

${ }^{19}$ En 1993, el Partido Socialista, incorporó un amplio programa para favorecer la igualdad de género que contaba con un apartado específico sobre violencia machista ("Violencia Doméstica"). En el documento, se proponían diferentes lineamientos, entre ellos, la colaboración estrecha con las instituciones (SERNAM) con el propósito de garantizar el "apoyo legal y psicológico de las mujeres víctimas de la violencia doméstica”. Ver Bachelet (1993: 20).
} 
"pocos intentos" ${ }^{20}$ de un gobierno por revertir las desigualdades estructurales que venían sufriendo las chilenas desde hacía décadas, a través de una regulación e infraestructura eficiente. En este contexto, se produjeron otros acontecimientos que apuntaban en esa misma dirección, tales como la aprobación de la Ley de cuotas $^{21}$ en algunos de los partidos más representativos de la transición (PPD y PS -1989) o la asunción de parte de la problemática de la violencia contra las mujeres por parte de las "principales organizaciones de trabajadores" 22 .

Durante el primer año de existencia del SERNAM, los planes y medidas elaborados se centraron en la regulación laboral y derechos asistenciales para las dueñas de casa. Una de las acciones más representativas que se implantaron en aquel momento, fue el "Programa de Apoyo a Mujeres Jefas de Hogar con Escasos Recursos" y el Centro de Información de los Derechos de la Mujer (CIDEM), cuyos objetivos estuvieron enfocados en "mejorar las condiciones económicas de las amas de casa, su salud y atención médica, evitar posibles discriminaciones salariales y laborales y promover la formación e inserción laboral"23. En esta línea, cabía de esperar, tal y como muestra la evolución histórica de los derechos de ciudanía de las mujeres a lo largo del siglo XIX y XX, que las instituciones comenzaran a regular los derechos de las mujeres en el ámbito público ${ }^{24}$, un espacio que entraña otro tipo dificultades "menos tediosas y complejas" que las discriminaciones de género reproducidas en el hogar, y en especial, con todo lo que tiene que ver con el maltrato.

\subsection{Las prioridades: cambios legislativos que garanticen la protección y apoyo integral de las víctimas}

En los inicios de la democracia, Chile no contaba con una legislación específica sobre violencia de género en el espacio privado. Tan sólo, el Código Penal, incluía una breve y ambigua referencia al asunto a través de su artículo ${ }^{\circ} 397$, que establecía sanciones leves aplicables al conjunto de miembros de una familia y, sin que el carácter vinculante entre cónyuge y maltratada fuera relevante. Por su parte, el Código civil hasta 1990, contenía un artículo (n¹35) que

\footnotetext{
${ }^{20}$ Esta situación nos recuerda a los tiempos de la Unidad Popular (1970-1990), cuando Salvador Allende Gossens trató de impulsar el Ministerio de la Familia (1972), proyecto de ley que fue rachado por la Democracia Cristiana en sesión parlamentaria. Ver Corvalán (2003).

${ }^{21}$ La ley de cuotas o también denominada discriminación positiva consiste en garantizar la participación femenina de al menos un veinte por ciento, especialmente en las respectivas direcciones centrales y políticas de los partidos. En el caso del partido socialista, esta medida fue criticada por un sector de la militancia, entre ellas, algunas mujeres, por considerar que en realidad se trataba de una medida que demolía el principio de meritocracia, lo que, desde su óptica, generaba situaciones injustas cuando no absurdas. Ver Maravall (2014: 195-211).

${ }^{22}$ En el IV congreso nacional de la Confederación Unitaria de los Trabajadores -CUT- celebrada durante 1991, se aprobó una resolución específica para las obreras centrada en "la denuncia y combate de la violencia sexual en los lugares de trabajo". Ver Valdés (2000: 55).

${ }^{23}$ Ibíd.: 56.

${ }^{24}$ Las primeras medidas de equiparación de derechos de ciudadanía de las chilenas estuvieron centradas en asuntos directamente relacionados con el espacio público: educación universitaria (Decreto Amunátegui, 1877) y sufragio universal femenino (1949).
} 
establecía la "legítima obediencia de la mujer al esposo"25, quién debía sustentar a cambio protección. El incumplimiento de este precepto moral, sería utilizado por muchos jueces para aplicar bajas penas a los maltratadores, cuando no sobreestimar las causas, lo que en sí mismo se traducía en una justificación moral de la violencia ante la desobediencia de género.

A partir de 1992, empezaron a sucederse las primeras propuestas dirigidas a un cambio legislativo que permitiera regular, de forma independiente, todo lo que tuviera que ver con la violencia ejercida contra las mujeres. Como se ha mencionado anteriormente, desde los años ochenta, las Ongs feministas venían utilizando el concepto de violencia doméstica para referirse a los malos tratos derivados de la convivencia entre un hombre y una mujer, sin establecer debates sobre nuevas categorías que especificasen con mayor precisión el fenómeno en toda su amalgama. Con la aparición del SERNAM, se utilizó el término "intrafamiliar" como una fórmula que debía integrar todos los tipos de violencias ocurridas entre los miembros de una misma familia, aunque en la práctica, el abordaje de la problemática se centró sobre todo en las mujeres. Así quedó reflejado en la primera acción gubernamental materializada en el " $1^{\circ}$ Programa Nacional de Prevención contra la Violencia Intrafamiliar", cuando se planteaban los asuntos prioritarios a trabajar: Erradicar la violencia contra las mujeres en el espacio doméstico, la elaboración de un diagnóstico nacional que permita conocer la magnitud del problema, la creación de "Centros de Atención a las mujeres y hombres agresores" 26 , la sensibilización y capacitación de funcionarios públicos y el impulso de una reforma legal acorde a las recomendaciones internacionales.

El programa solo llegó a implementarse en las comunas de Santiago, Conchalí y la Florida, teniendo un impacto ciudadano relativamente escaso. Es importante tener en cuenta que la aplicación y diseño de propuestas como ésta dependió, en buena medida, de la sensibilidad de los representantes políticos de cada región, en unos años en donde no era frecuente la formación en género. En la comuna de Conchalí, por ejemplo, su alcaldesa, María Antonieta Sáa (19911994), implementó de forma independiente, aunque con apoyo y asesoramiento del SERNAM, un proyecto pionero que en los años siguientes sería reproducido en otros sectores. De esta manera, en marzo de 1991 se inauguró el "Centro de Atención psicológica y legal de la mujer maltratada Julieta Kirkwood" "27, que benefició a cientos de mujeres. Aunque entre sus objetivos estaba "la incorporación y tratamiento del agresor, como parte del problema", las limitaciones financieras y la falta de infraestructura para realizar la captación y formación de hombres, hizo imposible llevarlo a la práctica.

\footnotetext{
25 "Lo primero que pregunta el juez al maltratador es: -¿señor, por qué pegó a su mujer?-, en la mayor parte de los casos responden: -porque mi mujer me desobedeció, le mandé planchar la camisa o servirme la comida y ella no quiso-", Ver Instituto de la Mujer (1991a: 61).

26 "La inclusión del agresor como parte del problema es de suma importancia, por cuanto deja de ser una política asistencial dirigidas a las mujeres consideradas solo en tanto víctimas, a las cuales se les entregan determinados beneficios para asumir las características de una política integral". Ver Instituto de la Mujer (1991b).

${ }^{27}$ El centro ofrecía atención psicológica y legal a las víctimas, información sobre derechos e instancias para protegerlos y acompañamiento en el proceso de denuncia en las diversas instancias judiciales.
} 
Dicho de otra manera, el déficit de recursos pero también de capital humano, fue la tónica predominante en lo que a políticas de género se refiere durante los primeros años de la democracia. Quizá no pesó tanto el déficit de voluntad política de los gobernantes, sino más bien las posibilidades reales de llevar a cabo una política efectiva a nivel nacional. Algunas historiadoras han planteado que, la principal institución que debía representar la garantía del cumplimento de los derechos fundamentales de las mujeres, contó de partida con "importantes deficiencias para su óptimo desarrollo" (Iglesias, M., 2006, pp. 933-936): escasa financiación para emprender políticas semejantes a las realizadas en el contexto internacional y carencia de personal especializado. Pese a ello, la institución desarrolló alternativas de acción que, con mayor o menor éxito, sí contribuirían a mejorar la calidad de vida de las mujeres y el desamparo de las víctimas, por ejemplo a través de cambios legislativos concretos.

Por ejemplo, Soledad Alvear, (primera directora general del SERNAM y de tendencia política democristiana), diseñó una novedosa hoja de ruta a través del " $1^{\circ}$ Plan de Igualdad de Oportunidades para las Mujeres 1994-1999”, (PIOM ${ }^{28}$, 1994), cuyo propósito, fue el de incorporar la igualdad de género en las políticas públicas como un elemento esencial en el proceso de recomposición democrática. Las prioridades, estuvieron centradas, por una parte, en los derechos asistenciales (Fuero Maternal y subvenciones a mujeres en situación de pobreza) y laborales de las mujeres (Ley sobre descanso dominical, regulación de permisos por enfermedad de los hijos, protección laboral de las trabajadoras embarazadas, etc.). En relación a la violencia de género, se redactó un apartado específico cuyos lineamientos proponían una política integral que abarcara amplios sectores de la sociedad pero también, el fortalecimiento del marco legal chileno: aprobación de una nueva ley de violencia intrafamiliar, capacitación a carabineros, jueces y funcionarios públicos, compromiso de los medios de comunicación para la difusión y sensibilización de la opinión pública, y la reforma del Código Penal en relación a los delitos sexuales (Ley 19617/1999).

El SERNAM logró, que el gobierno de Eduardo Frei Ruiz-Tagle (1994-1999) acogiera el PIOM I como una prioridad en su agenda política, un gesto que ayudó a reforzar la idea de que la violencia contra las mujeres debía considerarse como un problema del conjunto de la sociedad y en el que, los responsables políticos, debían involucrarse desde el mayor número de instancias posibles. Pero también se planteó la urgente necesidad de modificar el Código Penal para enmendar los vacíos legales, que "terminaban perjudicando a la víctima" 29 . En efecto, el

\footnotetext{
${ }^{28}$ El PIOM I, instaba a las autoridades chilenas a que ratificaran los acuerdos logrados en la Convención Interamericana para prevenir, sancionar y erradicar la violencia contra la mujer (Belém do Pará, Brasil, 1994), entre ellos, la necesidad de dotar a los Estados de la infraestructura necesaria para abordar el problema. Ello pasaba necesariamente por una adecuación de los respectivos marcos jurídico-legales para integrar la violencia machista como un delito de lesa humanidad con todos los efectos penales que conlleva.

29 "Las mujeres maltratadas, no pueden expulsar al agresor de la casa. En relación a las multas establecidas, muchas veces es restada del presupuesto familiar, sancionando con ello a las propias víctimas... La imposibilidad de recuperar efectos personales, en el caso que la víctima haya tenido que huir repentinamente del hogar resulta injusta a todos los efectos", Ver Rioseco (1994: 56).
} 
primer logro fue la aprobación de la Ley de Violencia Intrafamiliar ${ }^{30}$ (119325/1995) que tipificaba la violencia en el ámbito privado como un delito específico a sancionar. También la Ley de Filiación (1998) y la Reforma Constitucional (1999) ayudaron a garantizar un marco legal que protegiera de igual manera a hombres y mujeres en el ejercicio cotidiano de sus derechos. Al finalizar la década, el SERNAM elaboró un nuevo programa de acción (PIOM II, 2000-2010), centrado esta vez en tres aspectos fundamentales: la aplicación del principio de transversalidad de género en todas las acciones de gobierno, la puesta en marcha de diagnósticos sociales para conocer el alcance del problema, y la realización de campañas públicas de sensibilización y prevención para "promover la toma de conciencia sobre la violencia física, sicológica y sexual que sufren las mujeres"31. Otro de los avances destacables, se produjo cuando desde el SERNAM, se presionó a gobernantes y legisladores para que incluyeran en el Código Penal, el delito de Feminicidio (Ley 20.480/18/12/2010 ${ }^{32}$ ), un hito fundamental ya que implicó el aumento de penas para los maltratadores y mejoras en la protección de las mujeres. Asimismo, conviene mencionar que la progresión en la profundización de las medidas para edificar un marco legal adecuado, fue posible gracias al consenso entre la mayoría de los partidos con representación en la cámara de diputados, que sí aunaron esfuerzos para remar en una misma dirección, o así lo constata la aprobación por unanimidad de la mayoría de las propuestas legislativas. Quizá, tal y como ha ocurrido en otros países como en Francia, Suecia o Inglaterra, la sensibilidad en torno a la violencia contra las mujeres ha sido un elemento de cohesión democrática que ha traspasado las diferencias políticas en un sentimiento común de rechazo, tal y como ha ocurrido en otras materias como el terrorismo. En Chile, ello se vio evidenciado en una suerte de política "de suma y sigue” puesto que, los sucesivos ejecutivos democráticos tendieron a respetar el legado de sus predecesores. Por ejemplo, la regulación del Feminicidio se realizó durante la legislatura del presidente conservador Sebastián Piñera (2010-2014), un broche necesario que cerraba una década de trabajo previo, desarrollado durante los gobiernos socialistas de Ricardo Lagos y Michelle Bachelet (2000-2009); esta lógica se repetiría con las políticas dirigidas a la población masculina y las campañas publicitarias de sensibilización.

\footnotetext{
${ }^{30}$ El proyecto de ley sobre violencia intrafamiliar fue tramitado desde la cámara de diputados al senado durante el mes de abril de 1993. Este proyecto comprendía diversos puntos fundamentales: Creación del delito de violencia intrafamiliar (tanto física como psicológica). Establecimiento de nuevos procedimientos en la denuncia (puede denunciar cualquier persona que tenga conocimiento del delito en las distintas estancias de los cuerpos y fuerzas de seguridad del Estado). Establecimiento de Medidas cautelares al agresor. Entrega inmediata de los efectos personales de la víctima. Disposiciones favorables para la víctima en la tramitación del juicio. Prohibición de celebrar actos y contratos sobre bienes matrimoniales o propios de la víctima. Programas terapéuticos y de reinserción para agresor y víctima. Establecimiento de penas específicas y elevadas para lesiones graves o muerte.

${ }^{31}$ Ver lineamiento 1.2, PIOM II, SERNAM (2000).

${ }^{32}$ La Ley 20.480 estableció la figura del Feminicidio, a través de la modificación de la ley N ${ }^{\circ} 20.066$ sobre Violencia Intrafamiliar. Ello implicó el aumento de penas para el agresor en caso de que tuviera una relación de convivencia con la víctima (de 15 años a presidio perpetúo) y nuevas medidas de protección para la víctima (Medidas Cautelares canalizadas a través de los Tribunales de Familia). Ver www.sernam.cl
} 


\section{Políticas públicas con población masculina: “de las medidas de control y reinserción de los maltratadores a las acciones de prevención y reconfiguración del problema"}

\subsection{Primeros pasos: centros de atención y seguimiento para maltratadores}

La inclusión de los hombres en las políticas públicas centradas en la violencia contra las mujeres comenzó a darse tímidamente a principios de los años noventa mediante proyectos muy acotados. Esta primera etapa se caracterizó, por un lado, en el establecimiento de medidas exclusivamente relacionadas con la seguridad de la víctima, mediante un mayor control y seguimiento por parte de las fuerzas de seguridad del Estado, de los hombres condenados o con causas penales abiertas. Por otro, en la creación de centros de atención directa para la reinserción social del maltratador.

El primer antecedente lo encontramos en 1991, cuando el SERNAM, junto con el financiamiento de la Organización de los Estados americanos (OEA), implementó un programa pionero en el trabajo con hombres maltratadores ("Experiencia terapéutica con hombres golpeadores" $"$ ) cuyo propósito fue el de servir de contención en los casos de mayor urgencia, pero también, como un espacio de rehabilitación e inserción social del agresor. Aunque la experiencia no tuvo un impacto significativo (solo un centenar de hombres fueron atendidos), al menos, sí se obtuvo una primera radiografía de la realidad de los maltratadores y de su manera de entender, justificar y ejercer la violencia. En esta línea, las razones más mencionadas que "empujaron" a los hombres a acercarse a estos espacios fueron dos: porque la pareja lo denunciaba, abandonaba o amenazaba con separarse si no pedía ayuda. Porque el sujeto percibía cambios en la pareja fruto de los programas de sensibilización y formación para mujeres (empoderamiento femenino). Solo una minoría, entonces, habría solicitado atención de forma voluntaria por diferentes razones pero externas a la comprensión del problema.

Hubo que esperar al primer mandato presidencial de Michelle Bachelet (2006-2010) para que se creara la primera red de centros oficiales de atención en colaboración con el Cuerpo Nacional de Carabineros, institución que se encargaría de facilitar la infraestructura de seguridad necesaria para garantizar el seguimiento de los hombres condenados y potencialmente más peligrosos. Esta iniciativa pública, fue continuada por el gobierno del presidente Sebastián Piñera (2010-2014), período en el que se inauguraron otros seis centros especializados en distintas regiones del país. Sin embargo, durante ambos gobiernos, el problema se enfocó solamente en términos de seguimiento y reinserción del maltratador, con lo que quedó ausente una política de carácter preventivo, que abarcara a la población masculina en su conjunto, independientemente de que hubiera ejercido o no violencia. Ello no fue posible hasta 2012, cuando se planteó la creación de centros de atención abiertos (Programa Nacional con Hombres que Ejercen Violencia de Pareja-HEVPA-). Lo novedoso de este proyecto fue que tuvo un carácter integral ya que iba mucho más allá de las anteriores intervenciones acotadas a la

\footnotetext{
${ }^{33}$ Ignacio Baloaín, psicólogo del SERNAM, fue el encargado de aplicar el programa en el Centro de Violencia Doméstica de la municipalidad de Santiago (1991).
} 
creación de centros de atención directa solo a hombres agresores. Aunque entre sus prioridades se encontraba "la atención reeducativa de hombres que ejercen violencia con el fin de detenerla y que estos se responsabilicen de la misma" (SERNAM, 2015:15), cualquier hombre podía solicitar información y atención. Es decir, se planteó una fórmula abierta y de carácter preventiva basada en el voluntarismo de cada sujeto. Todavía es temprano para saber si los 15 centros del HEVPA que operan desde entonces, han tenido algún efecto concreto, tanto en la disminución de la violencia como en el grado de rehabilitación de aquellos hombres que pudieron ejercerla, aunque los datos de asistencia ofrecidos por el SERNAM no son muy alentadores: durante 2014 solo "fueron atendidos 1168 hombres" 34 , y la mayoría acudieron, no por voluntad propia, sino en el marco de sus obligaciones derivadas de su responsabilidad penal.

Estos resultados podrían interpretarse bajo dos ópticas: la información no estaría llegando suficientemente al colectivo de hombres para que hagan uso este recurso; las resistencias ante el cuestionamiento de las propias actitudes generaría rechazo a participar en este tipo de programas. De ser así, ello obligaría a repensar nuevas fórmulas para atraer a los hombres sin que se sientan "prejuzgados", que estuvieran encaminadas a generar espacios no relacionados explícitamente con la violencia machista, sino más bien con el ámbito de la salud mental y emocional de un determinado sujeto. De esta manera, podrían percibir el recurso como una oportunidad de mejorar su calidad y bienestar personal más que como una obligación o castigo por su manera de relacionarse con las mujeres.

\subsection{Impulso de referentes masculinos desde la intervención educativa}

Las políticas públicas dirigidas a moldear un determinado arquetipo masculino en relación a la igualdad y la violencia de género, partieron de propuestas de intervención educativa de carácter general para ambos sexos. El cuidado de la salud y la sexualidad en la población adolescente, la prevención de embarazos entre las jóvenes, y la resolución de conflictos en las primeras relaciones afectivo-sexuales, fueron temas que preocuparon al SERNAM desde un principio. Así, en 1994, junto con el Ministerio de Educación y Salud, se aprobó el Programa de Prevención Adolescente (PREA basado en la implementación de distintas jornadas de formación y sensibilización en materia de sexualidad, afectividad y cuidados corresponsables en la salud $\left(\mathrm{JOCAS}^{35}\right.$ ). Aunque ello no evidenciaba una política específica respecto al trabajo con hombres, al promover la corresponsabilidad en todas las esferas de desarrollo y, alternativas de buen trato en la resolución de conflictos, sí que de alguna manera empezaron a proponerse nuevas formas de entender lo masculino encaminadas a una práctica igualitaria efectiva. Esta política se reforzó a partir de 2005, cuando el SERNAM firmó el convenio de colaboración para la "Educación en la Resolución Pacífica de Conflictos con Población Preescolar" ${ }^{36}$, con la Junta

\footnotetext{
${ }^{34}$ Ver Memoria SERNAM (2014).

${ }^{35}$ Al finalizar el año 1996, se implementaron las Jornadas de Afectividad y Sexualidad en la comunidad educativa (alumnos, profesores y apoderados) en tres regiones (IV, VII y Metropolitana) y un total de 48 liceos, beneficiando a más de 27 mil estudiantes. Ver Memoria 1994-1996 SERNAM (1996: 56-57).

${ }^{36}$ Ver Plan de Igualdad de Oportunidades 2000-2010 (SERNAM, 2000: 40-43).
} 
Nacional de Jardines Infantiles (JUNJI), un hito importante porque significaba redirigir la mirada hacia los constructos masculinos y la violencia desde la más temprana infancia. Paralelamente, se impulsaron estudios y diagnósticos con población adolescente en relación a sus percepciones en las relaciones de "pololeo" y, en especial, en su manera de comportarse cuando se trataba de resolver un problema de pareja. En 2009, el SERNAM difundió algunos de los resultados obtenidos, a saber:

- Prevalencia de estereotipos sexuales basados en el dominio y subordinación: "el hombre por biología tiende a controlar sexualmente a la mujer"37.

- "Ser hombre = No mostrar emociones" $"$.

- La población joven y adolescente percibe que los hombres violentos son "de otra generación y, sobre todo, los que agreden físicamente" ${ }^{39}$.

- Falta de asunción de "responsabilidad en los actos violentos"40.

Para abordar estos obstáculos, durante la última legislatura de Michelle Bachelet, se puso en funcionamiento el Programa de Formación de Monitoras y Monitores Comunitarios en Prevención de la Violencia contra las Mujeres (SERNAM, 2015), cuyo lineamiento principal planteaba la formación integral de especialistas como fórmula preventiva entre la población más joven, por ejemplo, estimulando y difundiendo mediante talleres, conductas y modelos masculinos basados en el respeto y la plena igualdad con vistas a superar dichas creencias en torno a la manera de entender las relaciones de género y por sobre todo, la manera de entender "lo masculino".

\subsection{Creación de Diagnósticos y Estudios sobre Violencia y Masculinidad}

Al comenzar el nuevo siglo, empezaron a sucederse estudios institucionales exploratorios sobre la masculinidad y su relación con la violencia. Estas propuestas fueron impulsadas desde SERNAM en colaboración con otras Instituciones, como el Cuerpo Nacional de Carabineros, y organizaciones sociales como la Red de Estudios de la Masculinidad. En este punto, se han

\footnotetext{
${ }^{37}$ Una supuesta impulsividad del hombre sirve de justificante para determinados actos de violencia sexual (forzamiento, presión y acoso): "se da una sexualidad percibida como sin control, el hombre es un Animal...esta percepción es un argumento que puede ser utilizado como justificación de la violencia sexual o bien como una forma de justificar la no responsabilidad sobre sus comportamientos violentos", ver SERNAM (2009: 69).

38 Los hombres interpretan que los sentimientos y la emocionalidad son síntoma de debilidad, vulnerabilidad, falta de poder y autonomía, razón que utilizan para contenerlos. No relacionan este hecho con sus "estallidos de violencia", Ibíd.: 70.

${ }^{39}$ Interpretan la violencia machista como algo ajeno que rara vez se da entre los jóvenes. Hay una mayor deslegitimación de las conductas violentas de carácter físico entre la población masculina adolescente, no mencionan o identifican otro tipo de violencias: psicológica, control de movimientos, limitación de redes sociales, etc.

${ }^{40}$ El hombre es violento y no puede evitarlo ya que se trata de un instinto primario que aparece sobre todo en situaciones de conflicto: "El hombre es impulsivo, se le aprieta el botón y no puede detenerse", Ibíd.: 71.
} 
analizado los documentos más significativos (Informe de Carabineros de Chile -2005-2011-, Ministerio del Interior y Seguridad Pública, Informe Monográfico -2007-2012-, Observatorio de Equidad de Género en Salud -OEGS-, Programa “The International Men and Gender Equalitity Survey-IMAGES-CHILE, 2011-) obteniendo los siguientes resultados:

\subsubsection{Tipos de violencia ejercida por los hombres con mayor prevalencia}

- Conductas abusivas de carácter afectivo-sexual: presión y forzamiento para tener relaciones sexuales. El $10 \%$ de la población masculina en Chile, reconoce haber forzado o violentado sexualmente a una mujer a lo largo de su historia de vida y ello puede tener una relación directa con los estereotipos sexistas interiorizados por los hombres, por ejemplo, a través de los roles en la pornografía, el mercado o la cinematografía (cosificación de la mujer como objeto sexual en donde el hombre ocupa una posición dominante). También se alerta del aumento de transmisión de enfermedades de carácter sexual derivadas de la falta de autocuidados masculinos bajo la creencia de que es una responsabilidad que ha de recaer exclusivamente en la mujer.

- Conductas controladoras o abusivas en las relaciones sociales, la gestión del tiempo y las costumbres cotidianas: ¿Dónde está, con quién, cuándo llega o cómo se viste la pareja? suelen ser elementos frecuentes en un ciclo de la violencia machista. El miedo a la pérdida de la pareja (interpretada como posesión) suele ser el desencadenante de estas acciones, que los hombres justificaban en aras de mantener la unidad familiar y su propia dignidad masculina. También, dentro de esta categoría, se incluyeron la amenaza (generalmente con asesinarla, quitarle los hijos o autolesionarse si le abandona) y la presión o violencia económica, por ejemplo, a través del incumplimiento de las pensiones alimentarias o gastos familiares en la salud y educación de los menores.

- Violencia contra las pertenencias de la pareja, descalificaciones y lesiones físicas "leves": Estos tipos de maltrato suelen aparecer cuando la mujer no cumple con lo que se espera de ella y llama la atención cómo, en buena parte de los casos, los "ataques" se centran en la anatomía femenina y en su función sexual: no estar en buenas condiciones ("bonita y delgada") para satisfacer el deseo sexual del varón.

Por tanto, los resultados indican que las agresiones y tipos de violencia ejercida sobre las mujeres (hasta 2012) sobre todo tenían que ver como una fórmula de control de la mujer cuando se trata de tomar decisiones o gozar de derechos fundamentales: libertad de movimiento, la gestión del tiempo o el derecho a decidir sobre su sexualidad. Ello podría tener relación con los estereotipos tradicionales de género en cuanto a cómo debían ser las relaciones afectivas entre hombres y mujeres y en donde, históricamente predominó la idea de la mujer como objeto 
sexual y/o propiedad del varón ("La maté porque era mía”41). Para desmontar estas creencias, tal y como sugerían las recomendaciones del Informe Images, debían promoverse desde los medios de comunicación y él ámbito educativo, alternativas basadas en la igualdad de trato y respeto en las relaciones afectivo-sexuales, pero sin especificar cuáles debían ser los contenidos concretos a la hora de intervenir.

\subsubsection{Justificaciones de la violencia machista desde la óptica masculina}

- La violencia machista como instinto natural primario, que aparece en ciertas ocasiones y, su grado de intensidad, dependerá de las circunstancias personales del individuo (psicológica, como enfermedades de tipo mental o experiencias traumáticas de violencia en la infancia; y físicas, como el consumo de alcohol y estupefacientes, situación social y cesantía).

- La violencia es corresponsable: Aunque los hombres son los autores directos de los actos violentos, ellos mismos entienden que son respuestas ante las acciones provocadoras por las mujeres ("violencia psicológica"). Así, el hombre, desbordado ante las manipulaciones "retorcidas" de la pareja, terminaría "estallando en furia" y provocando violencia. Nuevamente, esta percepción viene a reforzar el determinismo biológico como la respuesta para entender las relaciones de género en situación de conflicto. Por naturaleza, los hombres estarían condicionados por su genética a ser físicamente más fuertes y por ende violentos, mientras que las mujeres, por sus características naturales, desarrollarían otras estrategias de supervivencia y defensa, que tendrían que ver con el espacio existencial asignado socialmente: desde lo íntimo, privado y emocional, dispondrían de otros mecanismos (maltratadores) más sutiles y psíquicos que servirían de justificación para que el hombre reaccionara violentamente como fórmula de auto-defensa.

- Prevalencia del estereotipo Hombre-Protector: Para cumplir esta función, predominan justificaciones de conductas violentas cuando aparece la posibilidad de que la pareja mantenga vínculos afectivos o sexuales con otros hombres. El problema se plantea en términos de "respuesta legítima violenta" ante la pérdida de la relación y la ruptura de la unidad familiar: "el $8,9 \%$ cree que una mujer debe tolerar que su pareja la golpee para mantener unida la familia" (Aguayo; Sadler, 2011: 115).

- La Violencia ante la negativa de la pareja de mantener relaciones sexuales: Uno de cada diez hombres adultos justifican los comportamientos violentos en determinadas ocasiones, específicamente, si la cónyuge se niega a tener relaciones sexuales o si ésta es descubierta en otra relación afectivo-sexual.

\footnotetext{
41 "La maté porque era mía" es una expresión popular utilizada para referirse a la violencia contra las mujeres en su dimensión de "crimen pasional", una concepción patriarcal en cuanto a que la mujer casada era percibida como propiedad del varón. Ver Muntané (2012).
} 
En base a estos resultados, la Red de Estudios de la Masculinidad planteó diferentes recomendaciones al SERNAM centradas en el trabajo específico con hombres a través de su formación y sensibilización en referentes masculinos pro-igualitarios en todas las esferas de la vida (el hombre tiene que aprender a ceder espacios de privilegio, a reconocer y gestionar sus emociones, a respetar los tiempos y deseos afectivo-sexuales de la pareja, en definitiva, a percibir a las mujeres como iguales). Efectivamente, se partió de la premisa de que para abordar el problema de la violencia masculina de una forma efectiva, había que incidir en la raíz del problema, esto es, en la interiorización de aquellas conductas que da alguna manera la justificaran o desencadenaran (sentimiento de control o pertenencia de la pareja, superioridad o protagonismo en la toma de decisiones familiares, reproducción de roles sexistas frente al trabajo doméstico y público, etc.). Por tanto, se asumió que las medidas institucionales de contención de los maltratadores aplicadas hasta el momento no habían sido eficaces porque:

1) La comprensión que hizo la institucionalidad del fenómeno no estuvo suficientemente relacionada con la socialización de género de la ciudadanía en modelos y creencias que lo justificaban y/o desencadenaban. Los esfuerzos estuvieron centrados más bien en paliar los efectos del problema más que en la comprensión de su origen.

2) La prevención integral con población masculina desde las primeras fases educativas no se consideró como una prioridad en las políticas públicas sobre violencia intrafamiliar

3) La formación de agentes de seguridad del Estado, funcionarios públicos, personal sanitario y educativo en políticas de prevención, atención y diagnóstico fue escasa (se refiere a la falta de credibilidad de los testimonios de las víctimas cuando denuncian).

4) Las campañas publicitarias y de difusión informativa estuvieron centradas en las víctimas y su protección, sin facilitar recursos a los hombres y mensajes adjuntos que ayudaran a la comprensión del problema.

5) Los recursos institucionales de atención psico-social (casas de acogida, programas de reinserción, etc.) estuvieron destinados solo a las mujeres, lo que implicó que el colectivo masculino se mantuviera en una posición estática.

\subsection{La Violencia contra las mujeres y su difusión en la sociedad}

Las campañas publicitarias contra la violencia de género son un fenómeno relativamente reciente en Chile. Solo a partir de 2005 encontramos los primeros registros de acciones encaminadas en este sentido. Aunque existieron algunas diferencias en los contenidos de las campañas que se diseñaron a partir de ese año (y hasta 2014), sí aparecen algunos elementos convergentes que apunta al orden de prioridades del SERNAM para afrontar el problema:

\section{- "La violencia contra las mujeres es un problema que atañe a toda la sociedad y las víctimas sobre todo tienen que denunciar"}

Uno de los mensajes utilizado desde las primeras campañas publicitarias del SERNAM hasta las últimas, es el de presentar el problema como un asunto que afecta al conjunto de la 
sociedad y por tanto, es responsabilidad de la ciudadanía involucrarse para resolverlo (" $L a$ violencia hacia la mujer nos daña a todos" ${ }^{\sharp 2}$ ). Se podría interpretar que ello supuso un avance significativo en cuanto que superaba el viejo estereotipo de que la violencia contra las mujeres es un asunto que ha de solucionarse en el espacio privado. ¿Pero de qué manera plantean las autoridades este compromiso? Como solución más visible frente a la violencia machista se propone el rechazo contundente y unánime (el uso del imperativo "No"43) sin que ello venga acompañado de elementos que ayuden a la comprensión del fenómeno. Se podría interpretar, en este sentido, un cierto apresuramiento por acotar el asunto a una solución clara e inmediata y cuya respuesta se plantea en términos cerrados y absolutos ("Entre un hombre y una mujer, maltrato cero ${ }^{\text {,44 }}$ ). Esta tendencia se confirma con otros elementos comunes a la mayoría de mensajes publicitarios; muestra de ello es, cómo las autoridades instaron a que las mujeres denunciasen su situación de maltrato a través de la inclusión de un número telefónico específico de atención (Fono Familia ${ }^{45}$ ).

Indudablemente, ello supuso un nuevo recurso que podría ser eficaz si éste iba acompañado del mensaje adecuado. Tal y como ha ocurrido en otros países con una amplia experiencia en el desarrollo de políticas de prevención en este terreno, el uso del tono imperativo ("Llama...no te quedes sin hacer nada" ${ }^{46}$, “iDenuncia!”47) no ha resultado ser eficaz para "animar" a las víctimas a que reaccionen y se pongan en contacto con las autoridades. En esta línea, en aquellos años ya existían estudios (Zurita, 2008, Bonino, 2008) que apuntaban a que dicha situación estaba relacionada con las dificultades intrínsecas que conlleva estar inmersa en una situación de malos tratos (en muchos casos de larga duración) que impedían que la víctima pudiera pedir ayuda. Efectivamente, el impacto emocional y psicológico de las agresiones, el temor a que su vida y la de sus hijos corran peligro "si habla", el desamparo económico añadido a una baja autoestima, suelen ser los elementos más comunes que sitúan a la mujer en un estado de paralización e indefensión difícil de sortear. Habría que esperar hasta 2010 para que se tomaran en cuenta algunos de estos obstáculos, por ejemplo, garantizando el anonimato de la denunciante ("Tu denuncia es anónima",48). Por consiguiente, el abordaje del problema se enfocó básicamente en el apoyo a las víctimas a través de la implementación de recursos específicos para identificar el problema y recibir atención para salir de la situación, lo que deja al colectivo masculino como un elemento ajeno a la solución del

\footnotetext{
${ }^{42}$ Ver campaña publicitaria SERNAM, 2005, www.sernam.cl

${ }^{43}$ La primera campaña publicitaria se realizó en 2005 bajo el lema "La violencia hacia la mujer nos daña: no la ejerzas, no la permitas, no la ampares", y en cuya imagen aparecen cuatro sujetos, dos hombres y dos mujeres levantando la mano. La utilización del imperativo, ha sido un elemento recurrente como forma de atención al ciudadano y que no solo atañen a la violencia de género sino a otras áreas, tales como la prevención de drogodependencias o accidentes automovilísticos. Ibíd.

${ }^{44}$ Ver campaña publicitaria SERNAM 2009. Ibíd.

${ }^{45}$ La campaña del año 2007 incluyó como novedad un número de teléfono (146) de atención a las mujeres. Ver campaña publicitaria SERNAM 2007. Ibíd.

46 Ibíd.

${ }^{47}$ Ver campaña publicitaria SERNAM 2010 y 2011. Ibíd.

${ }^{48}$ Ver campaña publicitaria SERNAM 2010. Ibíd.
} 
problema ya que, al fin y al cabo, la responsabilidad de denunciar terminaba recayendo en la mujer.

\section{- "Permanencia de estereotipos: Violencia de Género = Violencia Física, Hombre maltratador $=$ Hombre golpeador".}

Hasta 2012, las campañas publicitarias se centraron en la violencia física ("no me levantes la mano jamás",49,) tanto en las imágenes presentadas (un hombre por lo general que levanta la mano, golpea o empuja) como en el texto adjunto ("quien golpea a una mujer no es un hombre"). Sólo a partir de ese año, encontramos la inclusión de otro tipo de violencias más sutiles como la económica o la psicológica ("Quien te quiere te respeta"50, "Que te controle con la plata del mes es violencia" ${ }^{31}$ ). Efectivamente, el perfil de maltratador que se presenta desde las instancias públicas es un hombre que sobre todo agrede físicamente ante una mujer que no se puede defender. Otro elemento presente y que podría interpretarse como un retroceso en las políticas de igualdad, es la relación establecida entre violencia y "falta de hombría" llegando en algunos casos a utilizar expresiones homofóbicas ("Denuncia al maricón que maltrata a una mujer" ${ }^{\text {") }}$ )

Dichos mensajes reproducirían el ciclo de la desigualdad porque reflejaban estereotipos generados a partir de las creencias derivadas del modelo patriarcal. Así, ligar la figura del maltratador con el concepto de infra-hombre podría suscitar la creencia de que no se debe violentar a una mujer porque es más "débil" (por eso hay que protegerla), más allá de fomentar la idea de que se ha de respetar a las personas independientemente de cualquier otra consideración. En otras palabras, se podría interpretar que la figura del maltratador que se presentó desde las instituciones tenía que ver con un sujeto que sobre todo agredía por "cobardía" ("Maltratador = maricón”). La no inclusión de otras variables que, ya habían planteado las organizaciones de hombres y mujeres pro-igualitarias en sus respectivos trabajos (la incidencia de los celos y el control de la pareja en base al sentido de la propiedad, el escasa formación de los hombres en inteligencia emocional y resolución pacífica de conflictos, la simbiosis entre violencia y masculinidad a través de los juegos y juguetes del mercado, etc.) podría tener que ver con la falta de instancias en donde se intercambiaran experiencias y saberes entre la sociedad civil y, en este caso, el mismo SERNAM.

\section{- Últimas propuestas: la visibilización de otros tipos de violencia de género:}

La última campaña publicitaria implementada por el SERNAM en 2014, introdujo elementos novedosos que dan cuenta de un cierto avance, especialmente en lo que tiene que ver con la superación del estereotipo de violencia machista = violencia física. Para ello, la propuesta nombra y reflexiona sobre otro tipo de situaciones violentas y menos evidentes, en base a las creencias sobre lo masculino y la manera de relacionarse en pareja.

Una de ellas tiene que ver con el control ("Si tu pareja te pide las claves de tu correo, tu teléfono, tus redes sociales se quiere convertir en tu dueño. El control es una forma de violencia

\footnotetext{
${ }^{49}$ Ver campaña publicitaria SERNAM 2009. Ibíd.

${ }^{50}$ Ver campaña publicitaria SERNAM 2012. Ibíd.

${ }^{51}$ Ver campaña publicitaria SERNAM 2013. Ibíd.

${ }^{52}$ Ver campaña publicitaria SERNAM 2010-2011. Ibíd.
} 
contra las mujeres" ${ }^{53}$ ), como mecanismo ante el miedo a la pérdida de la pareja (física y emocional). Aunque no se proponen alternativas para que los hombres transformen estas actitudes (por ejemplo, relacionándolas con la autoestima o las emociones) sí, al menos, se enuncian y deslegitiman ante la ciudadanía, conductas características del modelo masculino hegemónico (Hombre $=$ Controlador).

Por otro lado, nombra otro tipo de circunstancias que pueden derivar en violencia como el que tiene que ver con la concepción masculina sobre la paternidad. Así, la ruptura de la pareja puede desencadenar el desentendimiento de los padres hacia el cuidado de sus hijos cuando no, la utilización de los menores como arma arrojadiza. En este sentido, se definen estos comportamientos como violencia específica hacia las mujeres ("aislamiento de sus familias y amistades, el dinero y de su vida privada...; las amenazas y la manipulación a través de las hijas o hijos" ${ }^{, 54}$ ) pero sin mencionar las causas o desencadenantes que las generan. Como se ha mencionado anteriormente, el propio SERNAM ya contaba con antecedentes de trabajo en este sentido (JOCAS ${ }^{55}$, 1996) que apuntaban a la necesidad de incluir en las campañas de información pública mensajes y recursos encaminados a fomentar modelos igualitarios, especialmente el referido a la comprensión de la paternidad y la corresponsabilidad en el cuidado de los hijos. Este desfase podría interpretarse por la ausencia de una coordinación efectiva entre quienes diseñan las campañas publicitarias y los profesionales encargados de implementar políticas públicas de intervención social.

\section{Conclusiones}

Desde 1990, nuestro país ha vivido un lento proceso en la construcción de políticas públicas para favorecer la igualdad de oportunidades en el conjunto de la ciudadanía. La carencia de un presupuesto acorde a las necesidades en este caso, de la violencia de género y la intervención socio-educativa con hombres, dificultó enormemente la puesta en práctica de acciones concretas que tuvieran un alto impacto social. Pero no solo se trató de limitaciones financieras puesto que también operaron otros factores a tener en cuenta. Uno de ellos fue la falta de experticia en la materia, tanto de los funcionarios públicos como en los representantes políticos.

La formación en prevención de la violencia machista y el trabajo para facilitar comportamientos igualitarios entre la población masculina, pasaba necesariamente por la comprensión del problema, un déficit que no cambió sustancialmente en tres décadas, o al menos, ello queda evidenciado en los mensajes institucionales estereotipados.

\footnotetext{
${ }^{53}$ Ver campaña publicitaria SERNAM 2014, Ibíd.

${ }^{54}$ Ibíd.

${ }^{55}$ Ver nota 35: 18 .
} 
Algunos expertos han planteado que en los 25 años de democracia, no han cambiado las políticas de género en su esencia, y tampoco se ha generado una cultura de re pensamiento profunda de las relaciones de género en su conjunto y, en especial, en la menara de entender y practicar lo masculino. Esta idea ha estado sustentada en que las actuaciones políticas se han diseñado a "partir de los esquemas y concepciones heredadas de la cultura tradicional" (Olavarría, 2001: 26), y sin tener en cuenta el impacto que la socialización de género ha tenido sobre las diferentes generaciones de chilenos y chilenas que conviven en la actualidad.

$\mathrm{Su}$ argumentación se basa en las cifras actuales de desigualdad en el país, que vienen a evidenciar la escasa influencia que las políticas gubernamentales han tenido en la ciudadanía durante las últimas décadas. Muestra de ello es cómo en 2014, el 65\% de las personas que viven en el país bajo el umbral de la pobreza siguen siendo mujeres, y son ellas las principales perjudicadas en los distintos tipos de violencia que se ejerce en el hogar y su lugar de trabajo. Las cifras en este sentido, lejos de disminuir, parecen tener una tendencia al alza, especialmente entre la población joven y adolescente. Es innegable que los asesinatos machistas han disminuido notablemente (62 feminicidios en 2007 frente a los 40 de 2014), pero también se han incrementado exponencialmente el número de denuncias (“60.769 en 2001 frente a 112.267 en $2012^{, 56}$ ).

Dicho de otra manera, en Chile mueren menos mujeres que hace diez años, pero son más las que sufren malos tratos, al menos, desde un punto de vista oficial. Evidentemente, ello no significa que porque las mujeres denuncien más, haya aumentado la violencia, pero sí habría una cierta lógica en que un mayor empoderamiento femenino podría haber desencadenado más agresiones.

Es precisamente en este punto donde ha podido entrar en juego el impacto de las distintas acciones institucionales emprendidas desde que se iniciara la democracia en la sociedad civil, especialmente las que tienen que ver con la difusión de información a través de los medios de comunicación masivos. En un mundo globalizado en donde las nuevas tecnologías han abierto infinidad de canales de información (entre ellas las que tienen que ver con la regulación y reflexión sobre la violencia machista), no sería descabellado pensar que un número considerable de chilenas, haya podido tomar conciencia de la necesidad de reivindicar sus derechos frente a las situaciones que las violentan o discriminan. Pero además de las campañas publicitarias e informativas, la puesta en marcha de recursos institucionales para garantizar la seguridad y el anonimato de las víctimas (casas de acogida, protección específica de los cuerpos y fuerzas de seguridad del Estado, programas de ayuda y capacitación socio-laboral, etc.) pudieron "animar" a miles de mujeres a denunciar su situación, independientemente de las dificultades que pudieran darse en el proceso.

Con la población masculina pudo darse un proceso similar pero a la inversa: el problema al ser nombrado, castigado penalmente y repudiado por la ciudadanía en su conjunto (los sucesivos gobiernos democráticos presentan la violencia machista como una cuestión que afecta

\footnotetext{
${ }^{56}$ Ver Instituto Nacional de Estadística (2013: 315).
} 
a toda la sociedad y en donde la respuesta en forma de rechazo ha de ser unánime) pudo servir como contención para un número indeterminado de hombres. En cualquier caso, las campañas sí llegaron masivamente a la población masculina, aunque solo una minoría se implicara directamente en alguno de los programas de prevención: "El 82,4\% de los hombres ha visto alguna vez un anuncio de televisión que cuestiona la violencia de género, un $45,7 \%$ ha escuchado de alguna campaña...y solamente un $12,7 \%$ ha participado alguna vez en una actividad que cuestione este tipo de violencia" (Aguayo y Sadler, 2011: 116)

Por consiguiente, los logros llegaron por otro lado. Durante la década de los noventa, los esfuerzos institucionales estuvieron enfocados a la protección jurídica de las víctimas y la generación de la infraestructura necesaria para atenderlas. Pero ello no vino acompañado ni de los recursos suficientes ni de otras políticas adjuntas que fueran en la dirección de la comprensión del problema para establecer medidas de calado. Es decir, si bien con la llegada de la democracia las mujeres fortalecieron su presencia en todos los terrenos del espacio público y la temática se incluyó como una prioridad en la agenda política, ello no conllevó una transformación de mentalidades, especialmente en lo que tiene que ver con la manera de entender la Masculinidad y la violencia contra las mujeres.

Efectivamente, en aquellos años se actuó en términos de protección más que de prevención, circunstancia que implicó dejar en un segundo plano el trabajo con hombres. Sólo en el último lustro, las instituciones comenzaron a tomar en consideración el trabajo con este colectivo como una alternativa que podría ser extraordinariamente beneficiosa a medio plazo gracias, fundamentalmente, a las aportaciones que se fueron realizado desde las Ongs de hombres y mujeres comprometidos con la igualdad. Asumir la prevención como una fórmula de trabajo para evitar futuros episodios violentos, es una política que entraña una serie de complejidades que, todavía desafortunadamente en Chile, no se han resuelto. Primeramente, porque no se ha logrado un consenso entre los diferentes especialistas del por qué se genera este tipo de violencia y cuál sería la manera más óptima de erradicarla. En segundo lugar, porque tampoco se generaron suficientes instancias de colaboración entre los actores sociales especializados y el SERNAM para el diseño de políticas eficaces, y ello quedó reflejado en los mensajes confusos y superficiales de las campañas de difusión informativa o en la falta de recursos para canalizar el problema que integraran a ambos sexos.

En este sentido, la intervención directa con hombres y mujeres desde la más temprana infancia, a través de la promoción de valores, conductas y herramientas basadas en la plena igualdad, pero también en la deconstrucción de los viejos paradigmas masculinos y femeninos desde todos los terrenos posibles (escuela, instituciones y mercado) ha sido una política muy reciente, lo que podría explicar la continuidad de los diferentes tipos de violencia que siguen existiendo en Chile y su relación con las creencias machistas que las desencadenan. Finalmente, no conviene olvidar un aspecto fundamental, todavía ausente en las políticas públicas relacionadas con la igualdad de género en Chile, que tiene que ver con el marco de 
posibilidades que abren las relaciones afectivo-sexuales que operan fuera de la heteronormatividad.

Tal y como apuntan estudios de reciente actualidad, aún "no existe un acuerdo por parte de la comunidad científica a la hora de establecer su prevalencia (la violencia)" (Otero, 2013: 103) puesto que, no se ha indagado lo suficientemente en el modus operandi del ciclo del maltrato en las distintas fórmulas de pareja, al igual que las variables en la manera de entender y ejercer lo femenino y lo masculino derivadas de la diversidad. Todavía es temprano para saber si ello podría implicar una nueva resignificación del problema de la violencia machista y de las relaciones de género en su conjunto.

\section{BIBLIOGRAFÍA}

- Abarca, María Elena (2015): La casa de la mujer La morada y el movimiento feminista, a través del testimonio, pensamiento, trayectoria y liderazgo político de Margarita Pisano (1983-1994). Santiago: Universidad de Santiago de Chile.

- Aguayo, Francisco; Sadler, Michelle (2011): Masculinidades y políticas públicas: involucrando hombres en las políticas de género. Santiago: Universidad de Chile.

- Aguayo, Francisco; Correa, Pablo; Cristi, Pablo (2011): Encuesta Images Chile: Resultados de la Encuesta Internacional de Masculinidades y Equidad de Género. Santiago: Cultura-Salud / EME.

- Aharonian, Aram (2003) (coord.): Vivencias: un taller para la memoria, Primer Encuentro Latinoamericano de Sobrevivientes de la Tortura. Santiago: FLACSO-Chile.

- Bachelet, Vivienne (1993): Programa Socialista de la Mujer: participación y protagonismo para los cambios. Santiago: Partido Socialista de Chile.

- Bonino, Luís (2008): Hombres y violencia de género. Más allá de los maltratadores y factores de riesgo. Madrid: Ministerio de Igualdad, Gobierno de España.

- Bourdieu, Pierre (2000): La dominación masculina. Barcelona: Anagrama.

- Burin, Mabel; Jiménez, María; Meler, Irene (2007): Precariedad laboral y crisis de la masculinidad. Impacto sobre las relaciones de género. Buenos Aires: Universidad de Ciencias Empresariales y Sociales (UCES).

- Bunster, Ximena (1983): La Tortura de Prisioneras politicas: un estudio de esclavitud sexual femenina. Rótterdam: Red Feminista Internacional Contra la Esclavitud Sexual Femenina y el Tráfico de Mujeres.

- Christian, Harry (1994): The Making of Anti-sexist Men. London: Routledge.

- Comisión Europea (2008): Manual para la perspectiva de género en las políticas de empleo, de inclusión social y de protección social. Luxemburgo: Oficina de Publicaciones Oficiales de las Comunidades Europeas.

- Connell, Rewan (1995): Masculinities. Cambridge: Polity Press.

- Corvalán, Luis (2003): El gobierno de Salvador Allende. Santiago: LOM. 
- Council of Europe Treatry Series (2011): Convenio del Consejo de Europa sobre prevención y lucha contra la violencia contra las mujeres y la violencia doméstica. Estambul.

- Covas, Susana; Bonino, Luis; Maravall, Javier (2009): Hombres con valores igualitarios: historias de vida, logros alcanzados y cambios pendientes. Madrid: Ministerio de Igualdad, Gobierno de España.

- Duby, George; Michelle, Perrot (2000): Historia de las mujeres (Volumen 5): Madrid: Taurus.

- Durán, Ma Ángeles (2012): El trabajo no remunerado en la economía global: Madrid: Fundación BBVA.

- Dudink, Stefan (2004): Masculinities in Politics and War. Gendering Modern History. Manchester : Manchester University Press.

- Gaviola, Edda; Largo, Eliana; Palestro, Sandra (1994): Una Historia necesaria, Mujeres en Chile: 1973-1990. Santiago: Aki \& Aora.

- Ministerio del Interior, Gobierno de Chile (1991): Informe de la Comisión Nacional de Verdady Reconciliación (ICNVR), Santiago: Ministerio del Interior.

. (2004): Informe de la Comisión Nacional sobre Prisión Política y Tortura (ICNPT), Santiago: Ministerio del Interior.

- INDL - Instituto Nacional de Derechos Humanos (2011): "Informe para la Calificación de Detenidos Desaparecidos, Ejecutados Políticos y Víctimas de Prisión Política y Tortura", [en línea] Disponible en: http:/www.indh.cl/wp-content/uploads/2011/10/Informe2011.pdf [15/01/2016].

- Instituto de la Mujer, Gobierno de Chile (1993): ¿Cómo les ha ido a las mujeres chilenas en la democracia?: balance de propuestas mirando al 2000. Santiago: Instituto de la Mujer.

. (1993): Violencia intrafamiliar, una problemática social. Santiago: Instituto de la Mujer.

. (1991a): Mujeres y Violencia Doméstica. Santiago: Instituto de la Mujer.

. (1991b): Modelos teóricos y metodológicos de intervención en violencia doméstica y sexual. Santiago: Instituto de la Mujer.

- Instituto Nacional de Estadística, Gobierno de Chile (2013): Informe Anual de Carabineros de Chile 2013. Santiago: INE.

- Iglesias, Margarita (2003): Género y globalización: Mujeres: feminismo, paridad, discriminación, violencia y sexismo. Santiago: Ed. Aún creemos en los sueños.

- Kaufam, Michael (2001): Effective Education With Boys and Young Men to Help End Violence. Canada: Government of Ontario.

- Maquieira, Virginia (2005): Democracia, Feminismo y Universalidad en el siglo XXI. Madrid: Universidad Autónoma de Madrid.

- Maravall, Javier (2014): Las mujeres en la izquierda política chilena durante la Unidad Popular y la Dictadura militar (1970-1990). Madrid: Universidad Autónoma de Madrid.

- Molina, Fernanda (2011): Crónicas de la hombría. La construcción de la masculinidad en la conquista de América. Buenos Aires: Universidad de Buenos Aires.

- Morant, Isabel (2006) (dir.): Historia de las Mujeres en España y América Latina (Vol. IV). Madrid: Cátedra. 
- Muntané, María Dolores (2012): La maté porque era mía: Psicobiología de la ira, la violencia y la agresividad, y de la sexualidad. Barcelona: Díaz de Santos.

- Observatorio de Equidad de Género y Salud (2012): Informe Monográfico (2007-2012). Santiago: Gobierno de Chile.

- Olavarría, José; Parrini, Rodrigo (2000): Masculinidad/es: identidad, sexualidad y familia: I Encuentro de Estudios de Masculinidade. Santiago: FLACSO.

- Olavarría, José (2001) (ed.): Hombres, identidades y violencia: $2^{\circ}$ encuentro de Estudios de Masculinidades: identidades, cuerpos, violencia y políticas públicas. Santiago: FLACSO.

- Otero, Luis Manuel (2013): "Desmitificación de la violencia en parejas del mismo sexo". En: Revista Iberoamericana de Salud y Ciudadanía, vol. II, n. 2, pp.102-110.

- Palestro, Sandra (1994): Una Historia necesaria, Mujeres en Chile: 1973-1990. Santiago.

- Pisano, Margarita (2009): Una historia fuera de la historia: biografia política de Margarita Pisano. Santiago: Revolucionarias.

- Rewan, Connell (1995): Masculinities. Cambridge.

- Rioseco, Luz (1994): Violencia Intrafamiliar y Legalidad. Santiago: Instituto de la Mujer.

- SERNAM - Servicio Nacional de la Mujer, Gobierno de Chile (1993): Comisión Interministerial para la prevención de la violencia familiar. Santiago: CEDOC-SERNAM.

. (1994): Plan de Igualdad de Oportunidades para las Mujeres 1994-1999. Santiago: Gobierno de Chile. . (1996): Memoria (1994-1996). Santiago: CEDOC-SERNAM.

Gobierno de Chile. SERNAM.

(2009): Análisis de la violencia en las relaciones de pareja entre jóvenes. Santiago: CEDOC(2012): Género y políticas públicas: avances y desafios en Salud. Santiago: CEDOCSERNAM. . (2014): Memoria SERNAM. Santiago: CEDOC-SERNAM.

. (2015): Atención, Protección y Reparación Integral de Violencias contra las Mujeres. Santiago: CEDOC-SERNAM.

- Valdés, Teresa (1987): Las Mujeres y la Dictadura militar en Chile. Santiago: FLACSO. $\overline{\mathrm{LOM}}$. . (2000): De lo social a lo político: la acción de las mujeres latinoamericanas. Santiago:

- Zurita, Evelina (2008): Del limbo al infierno: la construcción social de la violencia en las parejas. Huelva: Diputación de Huelva. 